\title{
THE PROBLEM OF SECURING TEACHERS OF COLLEGIATE MATHEMATICS FOR WARTIME NEEDS
}

The eighteen-year-old draft law and the inauguration of the proposed Army and Navy programs for colleges and universities are creating serious personnel problems for departments of mathematics. In an attempt to alleviate this situation, partially at least, the American Mathematical Society and the Mathematical Association of America are establishing in the Philadelphia Office of the Society a bureau to provide information regarding available teachers of collegiate mathematics. The cooperation of all mathematicians is needed in order to make this plan a success.

The government has indicated that approximately 250,000 trainees will be sent to a selected group of about 300 colleges and universities. It is estimated that the full-time services of at least 2500 teachers of mathematics will be required for this program. In addition, institutions will necessarily provide a normal program for men under 18 , for women, who are electing mathematics in increasing numbers, and for students rejected, for any reason, by Selective Service. Institutions will also continue special contracts already in existence such as meteorology and aviation pre-flight schools.

To provide for all this instruction there are available about 3,000 persons now functioning as teachers of mathematics in four-year colleges. To ensure the proper handling of this instruction, readjustments of and additions to teaching staffs of many institutions will be necessary. For some institutions, additional personnel might be secured from the following sources:

(1) Members of departments of mathematics in institutions which do not assume government programs;

(2) Persons now teaching in non-critical fields who have had sufficient training in mathematics to make them valuable in this field. These persons should be recruited for the teaching of mathematics rather than being allowed to assume non-academic employment. This should probably be the main source of supply.

It is in order to promote an orderly solution of these problems that the American Mathematical Society and the Mathematical Association of America have established the bureau of information regarding teachers of collegiate mathematics. The purpose is two-fold:

(1) To collect information concerning persons who are trained in mathematics and who are or will be available for teaching during the emergency at institutions other than their own. It is requested that 
the names and present addresses of persons who are available for employment as teachers of collegiate mathematics be reported to the address given below. Additional information concerning qualifications will be secured directly from the mathematicians so reported.

(2) To furnish to chairmen of departments of mathematics who need additional personnel the information obtained through (1). As the employment offered will, in most cases, be temporary, an attempt will be made to furnish the chairman with an adequate list, mainly of persons living in his vicinity. The purpose of the bureau is to furnish only information and not recommendations. The department chairman will, of course, investigate on his own responsibility the qualifications of the available teachers.

The country's awakened consciousness of the need for mathematics as a preparation for service in the armed forces imposes on the mathematical profession the grave responsibility to meet this need by providing the best possible teaching. The Society and Association aim to make a definite contribution to the war effort by supplying information regarding available teachers of mathematics. To do this, the full cooperation of all mathematicians is needed. It is impossible to predict what portion of the demand will be met in this manner. It is likely that teachers will become available less rapidly than the demands for additional personnel are made, but the cooperation of mathematicians will enable the bureau to function effectively.

All correspondence in this connection should be addressed to:

Committee on Available Teachers of Collegiate Mathematics

110 Bennett Hall

University of Pennsylvania

Philadelphia, $\mathrm{Pa}$.

March, 1943

Committee:

W. D. Cairns

ARnold Dresden

J. R. KLINE 